\title{
Does growth hormone treatment improve final height attainment of children with intrauterine growth retardation?
}

\author{
R Stanhope, M A Preece, G Hamill
}

\begin{abstract}
Twenty four children (five girls, 19 boys) who had intrauterine growth retardation were treated with daily subcutaneous biosynthetic human growth hormone, initially in a dose of either 15 or $30 \mathrm{U} / \mathrm{m}^{2} /$ week for the first year and in the latter dose for the next two years. Six patients (one girl, five boys) had no dysmorphic signs and 18 (four girls, 14 boys) had signs of Russell-Silver syndrome. All had birth weights below the third centile when adjusted for gestation age and all the children were below the third height centile at the start of treatment. Mean age was 6.3 years (range 2.1-9.7) when growth hormone treatment was started. All had normal growth hormone secretion to either a pharmacological or physiological test.

In the first year of treatment, height velocity SD score increased from -0.75 to +3.6 in the group treated with $30 \mathrm{U} / \mathrm{m}^{2} /$ week, and from -0.77 to +1.4 in the lower dose group. After three years of treatment, mean height velocity SD score was $+1 \cdot 1$, irrespective of which initial treatment dose had been administered during the first year. There was no difference in the growth response of children with or without dysmorphic features. However, despite the sustained increase in growth rate, there was no significant change in height for bone age SD score, pointing to an unaltered final height outcome.
\end{abstract}

Growth hormone has been used in the treatment of children with growth hormone deficiency for more than 20 years. Such physiological replacement treatment increases growth velocity and allows the restoration of growth prognosis from the onset of treatment, but in 'standard' dose regimens of between 12 and $15 \mathrm{U} / \mathrm{m}^{2} /$ week does not improve final height prognosis beyond the potential at the start of treatment ${ }^{1}$; growth hormone treatment allows that potential to be attained. However, since the advent of potentially unlimited supplies of biosynthetic human growth hormone, the pharmacological use of the hormone has been explored in the treatment of short stature which is not due to growth hormone deficiency. The use of growth hormone treatment in short normal children, ${ }^{2}$ Turner's syndrome, ${ }^{3}$ skeletal dysplasias, ${ }^{4}$ low birthweight syndromes, ${ }^{5}$ and chronic renal failure ${ }^{6}$ has demonstrated that such treatment produces an improvement in short term growth rate. It is only in Turner's syndrome that treatment with growth hormone has shown convincing evidence of improved final height attainment. ${ }^{3}$ Higher doses of hormone, equivalent to that in naturally occurring pituitary gigantism, would theoretically lead to an improved final height but there may well be adverse metabolic sequelae. ${ }^{7}$ The pharmacological use of growth hormone in children with short stature has been in the dose range of $15-30 \mathrm{U} / \mathrm{m}^{2} /$ week, although $40 \mathrm{U} / \mathrm{m}^{2} /$ week has been used in children without changes in glucose tolerance. ${ }^{8}$

Intrauterine growth retardation (IUGR) may be associated with postnatal growth failure and result in a final height in the region of $-3.6 \mathrm{SD}$ score. ${ }^{9}$ The pattern of growth in such children continues to be abnormal from intrauterine life through to full maturity. Growth in the first two years of life, which is predominantly dependent on nutrition and growth factors rather than growth hormone, is subnormal. ${ }^{10}$ Growth in the middle childhood years, which is predominantly growth hormone dependent, ${ }^{10}$ may be due to abnormalities in quantity ${ }^{11}$ and quality ${ }^{12}$ of endogenous growth hormone secretion. The adolescent growth spurt usually occurs early and is reduced in magnitude. ${ }^{9}$

Previous authors have reported an increase in growth velocity in some children with short stature secondary to IUGR but have used growth hormone doses between 30 and $65 \mathrm{U} / \mathrm{m}^{2} /$ week. ${ }^{13} 14$ The relatively poor response may have been due to the frequency of administration being only two or three times per week. Using a more optimal frequency of daily administration, a satisfactory growth response has been reported using a lower dose regimen. ${ }^{11} 1516$ Eighteen month growth velocity data have been reported in children with IUGR treated with growth hormone ${ }^{17}$ but despite a large group of patients, these did not include children with RussellSilver syndrome.

Previous studies with smaller numbers ${ }^{11}{ }^{13-17}$ have not treated patients for uniniterrupted periods of greater than two years. We describe three year data on both growth velocity and growth prognosis in 23 children with short stature and low birth weight, the majority of whom had Russell-Silver syndrome, treated with daily growth hormone. During the first year of this trial, the dose regimen was randomised to either 15 or $30 \mathrm{U} / \mathrm{m}^{2} /$ week and has previously been reported ${ }^{5}$ but only in terms of changes in short term growth velocity. We now present three year data on both linear growth and epiphyseal maturation which together point to final height prognosis.

Patients and methods

Twenty four prepubertal patients (five girls, 19 boys) were treated with biosynthetic human 
growth hormone. All had heights below the third centile for chronological age and birth weights less than 2 SD below the mean for gestational age. On clinical examination the children were divided into two groups: those with signs of Russell-Silver syndrome and those without. The criterion used were typical facies, hands and body asymmetry. Minor signs alone, such as clinodactyly of the fifth finger, were considered insufficient evidence of Russell-Silver syndrome. Six patients (one girl, five boys) had no dysmorphic signs and 18 (four girls, 14 boys) were classified as Russell-Silver syndrome. Mean age was $6 \cdot 3$ years (range $2 \cdot 1-$ 9.7) at the commencement of hormone treatment. All patients had a normal peak serum response (growth hormone concentrations $>10$ $\mu \mathrm{g} / \mathrm{l}$ ) to either a pharmacological test (response to insulin induced hypoglycaemia or glucagon) or a physiological test ( 10 hour overnight blood sampling at 15 minute intervals) of growth hormone secretion. It was not the aim of this study to treat children with hormone insufficiency.

All growth hormone was administered by daily subcutaneous injection. The dose was calculated on a surface area basis and updated every six months. During the first year of treatment patients were randomised into two groups: 13 (four girls, nine boys) were treated with $30 \mathrm{U} / \mathrm{m}^{2} /$ week and 11 (one girl, 10 boys) were treated with $15 \mathrm{U} / \mathrm{m}^{2} /$ week. Chronological age and pretreatment growth rate were similar between the two groups. During the second and third years of this trial all patients were treated with growth hormone in a dose of $30 \mathrm{U} / \mathrm{m}^{2} /$ week.

Growth was assessed by standard anthropometric techniques ${ }^{18}$ at intervals of six months and compared with the standards of Tanner $e t$ $a l .{ }^{19}$ Bone age was assessed by the methods of Tanner et $a l^{20}$ by one trained observer, performed in a blind fashion. Statistical analysis was by paired $t$ test.

\section{Results}

In the first year of the trial, mean height velocity SD score increased from -0.75 to +3.6 $(\mathrm{p}<0.001)$ in the patients treated with $30 \mathrm{U} / \mathrm{m}^{2} /$ week (fig 1). By contrast, those treated with the lower dose regimen accelerated from a mean height velocity SD score of -0.77 to +1.4 $(p<0.01)$. Because of the improved short term growth velocity using the higher dose regimen, all the patients continued in the second and third years of the study on the higher dose regimen of $30 \mathrm{U} / \mathrm{m}^{2} /$ week. Growth velocity $\mathrm{SD}$ score was sustained at a mean of $+1 \cdot 1$ after three years, irrespective of which initial treatment group was selected, which was significantly different from pretreatment growth velocity $(p<0.01)$. There was no difference in the response between the sexes or between those with or without Russell-Silver syndrome (fig l). No adverse effects were experienced and there was no significant change in fasting blood glucose and glycated haemoglobin $\left(\mathrm{HbA}_{1 \mathrm{c}}\right)$ concentrations.

The individual growth responses were heterogeneous. One patient (without Russell-Silver syndrome) had no significant improvement of

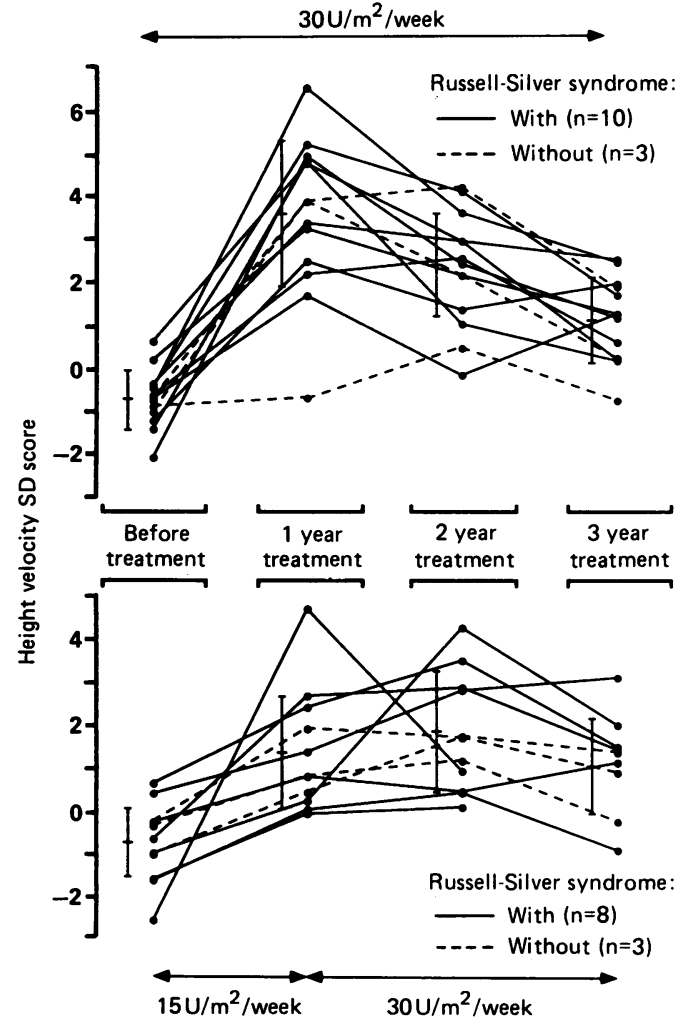

Figure 1 Height velocity $S D$ score in 24 children with short stature secondary to intrauterine growth retardation, both before treatment and during threeyears of growth hormone treatment. The children were treated with a growth hormone dose regimen of either 15 or $30 \mathrm{U} / \mathrm{m}^{2} /$ week during the first year and during the second and third years all children were treated with the higher dose regimen.

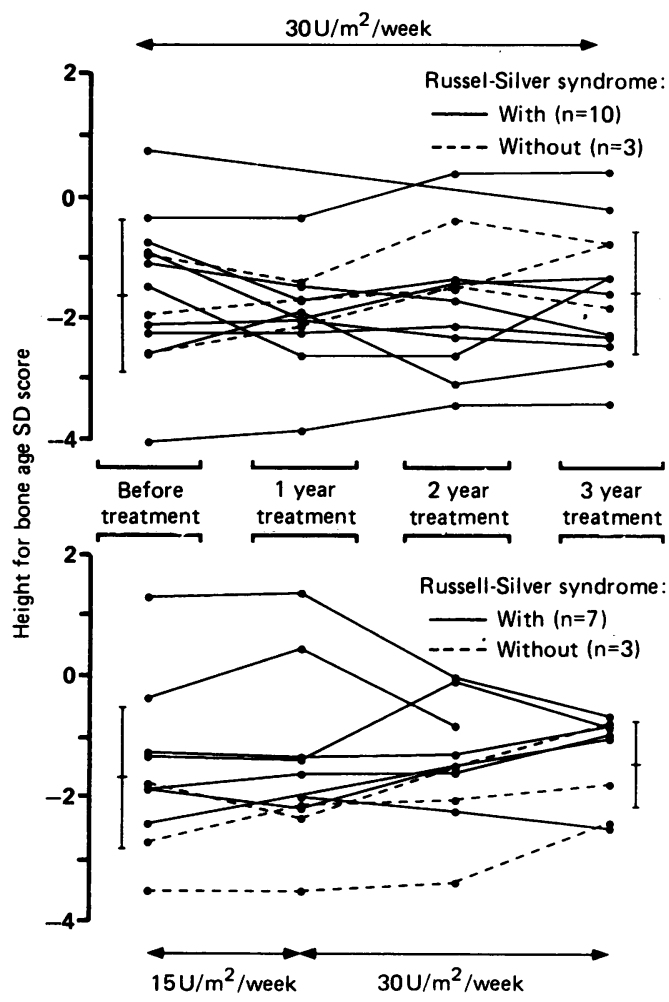

Figure 2 Height for bone age SD score in 24 children with short stature due to intrauterine growth retardation both before treatment and during threeyears of growth hormone treatment.

growth velocity after nine months of treatment with the lower dose regimen and withdrew from this trial. Mean height of the parents was $-3 \cdot 2$ 
SD score and there was probably an alternative diagnosis in addition to low birth weight to account for this girl's short stature. Two boys with Russell-Silver syndrome, both in the lower dose regimen during the first year, ceased treatment during the third year of the study. One discontinued treatment because the parents were dissatisfied with the response, the other due to non-compliance with the treatment. Only one patient without Russell-Silver syndrome had an inadequate response to growth hormone treatment despite being in the higher dose regimen during the first year: growth velocity SD score was $+0 \cdot 4$, and after three years she had a similar value.

Height for bone age score, as a measure of growth prognosis, showed no significant difference $(p>0.5)$ throughout the study from a mean value of -1.6 in both groups at the outset of treatment to -1.5 after three years (fig 2). There was no difference between those children who were treated with the high dose $(-1 \cdot 6)$ and low dose $(-1.4)$ regimens during the first year of the trial.

\section{Discussion}

Children with short stature secondary to IUGR, irrespective of whether dysmorphic signs were present or not, probably represent multiple aetiologies and it is not surprising that there was a heterogeneous growth response to growth hormone treatment. Certainly the children treated with the higher dose regimen grew much faster and it was for this reason that all the children were changed during the second and third years of the study to the higher dose. There was a significant improvement of linear growth response, which continued for at least three years. However, there was no evidence of improved final height, using height for bone age SD score as a measure of height prognosis. The effect of treatment with growth hormone appeared to be an alteration in the 'tempo' of growth without this being translated into improved height prognosis.

Children with IUGR syndromes have an inappropriate advance in epiphyseal maturation which is related to the short adult stature attainment of a mean of -3.6 SD. ${ }^{9}$ It may be that, in a similar way to patients with classical growth hormone deficiency, ${ }^{1}$ our patients will attain a final stature which is appropriate for height and bone age to that at the onset of growth hormone treatment. As there was no decrease in height for bone age SD score, which presumably must occur in untreated IUGR children ${ }^{9}$ associated with inappropriate advance of epiphyseal maturation, it may be that our treated patients will have a greater final height than they would otherwise have attained. However, as with any child with a dysmorphic syndrome, the comparison of epiphyseal and metaphyseal morphology, which is fundamental to all methods of bone age determination, may point to a false impression of how much growth potential remains. Only the continuation of clinical trials such as this until final height, will answer the question.

We are uncertain of the effects of growth hormone treatment during puberty in IUGR children. After three years of our study, all the children remained prepubertal. The growth spurt of puberty is abnormal in children with IUGR $^{9}$; the onset of puberty occurs earlier and there is a lower peak height velocity than in normal children. There is historical ${ }^{21}$ and randomised trial ${ }^{22}$ data to suggest that growth hormone treatment of children with isolated deficiency of growth hormone results in a reduction in the duration of puberty which is probably dose dependent. ${ }^{22}$ Moreover, this effect, especially using the high pharmacological doses that we have used, may further compromise pubertal growth. It may be advantageous to delay the onset and duration of puberty using a gonadotrophin releasing hormone analogue $^{22}$ to permit a longer period for growth in prepuberty and puberty.

There are many other potential indications for the use of growth hormone for short stature when there is no hormone deficiency with the belief that growth hormone treatment will improve final height. Certainly there is considerable evidence to this effect in the treatment of girls with Turner's syndrome ${ }^{3}$ but convincing evidence is lacking in other patient groups, including IUGR. There may be considerable psychological benefit from improving growth in children with short stature during the middle childhood years ${ }^{23}$ but it is probable, at least in IUGR children, that it is only the 'tempo' of growth that is altered without a corresponding increase in final stature. The initial promise of the therapeutic application of abundant supplies of biosythetic growth hormone in the treatment of children with short stature may not be realised. ${ }^{25}$

Gail Hamill was supported by the Child Growth Foundation. We are indebted to Serono (UK) (Ms Ursula Mason, Mr C Eyre, Ms Janis Clayton, and Mr Paul Thomas) for financial, secretarial, and administrative support with this study. We are grateful to Professor A Aynsley-Green and the late Professor M Parkin, Royal Victoria Infirmary, Newcastle upon Tyne, for their help with the treatment of one of the patients in this trial.

1 Bundak R, Hindmarsh PC, Smith PC, Brook CGD. Longterm auxologic effects of growth hormone. $\mathcal{J}$ Pediat 1988 ; 112:875-9.

2 Hindmarsh PC, Pringle PJ, Di Silvio L, Brook CGD. Effects of three years of growth hormone therapy in short normal of three years of growth hormone therapy in short
children. Acta Paediatr Scand 1990;suppl 366:6-12.

3 Rosenfeld RG. Update on growth hormone therapy for Turner's syndrome. Acta Paediatr Scand 1989;suppl 356: 103-8.

4 Appan S, Laurent S, Chapman M, Hindmarsh PC, Brook CGD. Growth and growth hormone (GH) therapy in hypochondroplasia. Horm Res 1989;31(suppl): 43.

5 Stanhope R, Ackland F, Hamill G, Clayton J, Jones J, Preece MA. Physiological growth hormone secretion and response to growth hormone treatment in children with short stature and intrauterine growth retardation. Acta Paediatr Scand 1989;suppl 349:47-52.

6 Fine RN. Recombinant human growth hormone treatment of children with chronic renal failure: update 1990 . Acta Paediatr Scand 1990;suppl 370:44-48.

7 Davidson MB. Effect of growth hormone on carbohydrate and lipid metabolism. Endocr Rev 1987;8:115-31.

8 Bougneres PF. High-dose growth hormone treatment of nongrowth hormone-deficient children: preliminary results growth hormone-deficient children: preliminary result
after two years. Acta Paediatr Scand 1990; suppl 366:38-40.

9 Davies PSW, Valley R, Preece MA. Adolescent growih and pubertal progression in the Silver-Russell syndromc. Arch pubertal progression in

10 Brook CGD. The treatment of growth deficiency. Clin Endocrinol 1988;29:197-204.

11 Albertsson-Wikland K. Growth hormone secretion and growth hormone treatment in children with intra-uterine growth retardation. Acta Paediatr Scand 1989;suppl 349: $35-41$.

12 Ackland FM, Stanhope R, Eyre C, Hamill G, Jones J, Preece MA. Physiological growth hormone secretion in children with short stature and intra-uterine growth retardation. Horm Res 1988;30:241-5. 
13 Tanner JM, Whitehouse RH, Hughes PCR, Vince FP. Effect of human growth hormone for one to seven years on growth of 100 children, with growth hormone deficiency, low birth weight, inherited smallness, Turner's syndrome and othe complaints. Arch Dis Child 1971;46:745-82.

14 Grunt JA, Enriques AR, Daughaday WH, Budd S. Acute and long-term responses to $\mathrm{hGH}$ in children with idiopathic small-for-dates dwarfism. F Cin Endocrinol Metab 1972;35: 157-68.

15 Foley TP Jr, Thompson RG, Shaw M, Baghdassavian A, Nissley SP, Blizzard RM. Growth responses to huma growth hormone in patients with intra-uterine growth retardation. F Pediatr 1974;84:635-41.

16 Lanes R, Plotnick LP, Lee PA. Sustained effect of human growth hormone therapy on children with intra-uterine growth retardation. Pediatrics 1979;63:731-5.

17 Job JC, Sagnard L, Chatelain P, Vanderschueren M. Treatment with growth hormone $(\mathrm{GH})$ in non-GH deficient shor children with intra-uterine growth retardation (IUGR) results after eighteen months of a dose/response study. Horm Res 1990;33(suppl 3):23.
18 Brook CGD. Growth assessment in childhood and adolescence. Oxford: Blackwell, 1982

19 Tanner JM, Whitehouse RH, Takaishi M. Standards from birth to maturity for height, weight, height velocity and weight velocity: British children, 1965. Part II. Arch Dis Child 1966;41:613-35.

20 Tanner JM, Whitehouse RH, Cameron N, Marshall WA, Healy MJR, Goldstein H. Assessment of skeletal maturity and prediction of adult height (TW2 method). 2nd Ed. London: Academic Press, 1983.

21 Darendeliler F, Hindmarsh PC, Preece MA, Cox L, Brook CGD. Growth hormone increases rate of pubertal maturation. Acta Endocrinol 1990;122:414-6.

22 Stanhope R, Uruena M, Hindmarsh P, Leiper AD, Brook CGD. Management of growth hormone deficiency through puberty. Acta Paediatr Scand 1991;(suppl)372:47-52.

23 Skuse $D$. The psychological consequences of being small. f Child Psychol Psychiat 1987;28:641-50.

24 Buckler JMH. Psychological consequences of being short or tall. Growth Matters 1990;1:2-3.

25 Milner RDG. Which children should have growth hormone therapy? Lancet 1986;i:483-5.

\section{Salbutamol in bronchiolitis}

Last year in a report from Toronto it was claimed that nebulised salbutamol (albuterol in the United States) was effective treatment in bronchiolitis. " Now workers in Ottawa have produced similar results (Terry PK Lassen and colleagues, Fournal of Pediatrics 1991;118:807-11).

They performed a randomised, double blind trial comparing nebulised salbutamol with placebo (normal saline). The salbutamol treated patients had a slightly but significantly greater heart rate at 60 minutes after the treatment but there were no significant differences in respiratory rate or oxygen saturation between the two groups at 30 or 60 minutes. The main outcome measure was a clinical score of wheeze and chest retraction (the respiratory distress assessment instrument, RDAI), which gives a score from 0 to 17. The median score before treatment was 8.75 in the treatment group and 8.0 in the placebo group. 30 minutes after treatment the median scores were 6.0 and 7.75 respectively ( $\mathrm{p}=$ 0.04).

I have two difficulties with this work. Firstly, the definition of bronchiolitis used in the study includes any wheezing child below the age of 2 years who is not known to have had asthma in the past. Only $58 \%$ of the patients had respiratory syncytial virus infection. Secondly, I'm uneasy about the application of statistics in this way to arbitrarily derived clinical scores. The RDAI score is an entirely artificial and contrived parameter. How can it be treated statistically in the same way as a measured continuous variable such as height, oxygen tension, or heart rate? What, too, is the relationship between statistical significance and clinical significance? Shouldn't authors be encouraged to do more to recognise the distinction? On the face of it a difference in change of 2.5 on a 17 point scale doesn't seem all that much, especially as the two observers might differ by up to two points in paired observations. The orginators of the RDAI defined clinical improvement as a fall of at least four points in the score and confined their statistical analysis to responders and non-responders on that basis. ${ }^{2}$

It-seems likely to me that many of the children in these North American trials might have been thought by British paediatricians to be suffering from asthma or 'wheezy bronchitis'. I have doubts about the relevance of the results to the management of epidemic bronchiolitis. 